DOI: 10.20472/IAC.2018.043.055

MIYU YADA

Department of Urban and Civil Engineering, Graduate School of Integrative Science and Tokyo Engineering, TOKYO CITY UNIVERSITY, Japan

\author{
TAKASHI NAKAMURA \\ TOKYO CITY UNIVERSITY, Japan
}

\title{
ACTUAL CONDITION OF EMPLOYEE NUMBER IN JAPANESE LOCAL CITIES' CENTRAL AREAS
}

\begin{abstract}
:
In Japan, the decline of the central district is one of the most serious urban problems.

It is caused by decreased commercial function and the urban sprawl with disorderly constructed large commercial complex and motorization. In this study, we investigate employee number trend in the central district and suburban area. This study targets 35 cities with population ranging from over 100,000 to less than 400,000 that do not fall in the three major metropolitan areas (Tokyo, Nagoya and Osaka) and We confirm actual employee number in central district from 2009 to 2014 and population from 2010 to 2015 .This study analyses the relationship between population and employee number, especially paying attention to "Wholesale and retail trade" , " Finance and insurance" ," Scientific research, professional and technical service ", " Accommodations eating and drinking service", "Education, learning support" and "Medical, health care and welfare" which account for a higher proportion in all industry types in central district and have distinctive trends. As a result the following points were demonstrated. A: Although the employee number in almost cities is on a decreasing trend, the employee number of" Medical, health care and welfare" in central district clearly is clearly on an increasing trend in all cities.B: Although the employee number of almost industry types is clearly on a decreasing trend, the employee number of "Scientific research, professional and technical service " and "Education, learning support" is a more slowly decreasing trend than others.
\end{abstract}

\section{Keywords:}

employee number, Central district, revitalization of local cities

JEL Classification: R58, R14, R52 